RESEARCH ARTICLE

\title{
PROBLEMATIKA UNDANG-UNDANG NO 35 TAHUN 2009 TENTANG NARKOTIKA DALAM HAL PENERAPAN REHABILITASI BAGI PENYALAH GUNA NARKOBA
}

\author{
Ardya Rahma Kusumasari \\ Program Studi Magister Ilmu Hukum, Universitas Negeri Sebelas Maret \\ $\triangle$ ardyarahma01@gmail.com
}

\begin{abstract}
The criminal law enforcement process in Indonesia is very unique, multidimensional and destructive, seen in the law enforcement process, especially in the settlement of drug criminal cases, where in the process there are many deviations from the applicable laws, so that someone who is not guilty of an error in sentencing will be declared wrong. . Along with the times, the Indonesian state immediately fixes and enhances development by achieving the prosperity of the Indonesian people fairly based on Pancasila and the 1945 Constitution of the Republic of Indonesia (UUD 1945). The problem in this paper is how to deviate from the Articles of the Narcotics Law in terms of implementing rehabilitation? and How are the case problems caused by the application of the articles in the Narcotics Law? The method used is using normative research methods. The results of the research in the application of the Articles of the Narcotics Law. Many deviations from this will have an impact on drug abusers and addicts who lose their rehabilitation rights.
\end{abstract}

Keywords: Narcotics, Application, Rehabilitation

Proses penegakan hukum pidana di Indonesia sangat unik, multidimensi serta destruktif, dilihat proses penegakan hukum khusunya dalam penyelesaian kasus pidana pecandu naroba, dimana dalam prosesnya banyak terjadi penyimpangan dari aturan perundangundangan yang berlaku, sehingga seseorang yang tidak bersalah dengan kesalahan penjatuhan hukuman akan dinyatakan bersalah. Seiring perkembangan zaman, negara Indoneisa segera membenahi dan meningkatkan pembangunan dengan tujuan untuk mencapai kemakmuran masyarakat Indonesia adil berdasarkan pancasila dan undangundang dasar negara Republik Indonesia Tahun 1945 (UUD 1945) pembangunan tersebut dibidang hukum. Permasalahan dalam penulisan ini adalah Bagaimana penyimpangan pasal UU Narkotika dalam hal penerapan rehabilitasi ? dan Bagiamana permasalahan kasus yang terjadi akibat adanya penerapan pasal dalam UU Narkotika ?. Metode yang digunakan yaitu menggunakan metode penelitian normatif. Hasil penelitian dalam penerapan pasal UU Narkotika banyak terjadi penyimpangan hal ini akan berdampak pada penyalah guna maupun pecandu narkotika yang kehilangan hak rehabilitasinya.

Kata Kunci : Narkotika, Penerapan, Rehabilitasi 


\section{INTRODUCTION}

Indonesia sebagai negara yang mengadopsi Konvensi Tunggal Narkotika 1961 beserta Protokol yang mengubahnya, mengacu pada prinsip-prinsip Political Declaration and Plan Action of 2009, dalam kebijakan penanganan narkotika dengan menggunakan Balance Approach antara demand reduction and supply reduction. Dalam Undang-Undang No. 35 Tahun 2009 tentang Narkotika telah mengacu pada pendekatan Balance Approach, di mana dalam pendekatan terhadap demand reduction difokuskan melalui kegiatan.

Rehabilitasi penyalahguna dan pecandu narkotika, dengan tujuan menyembuhkan kondisi sakit ketergantungan narkotika terhadap para penyalah guna dan pecandu agar penyalah guna dan pecandu sembuh dari penyakit adiksi/ketergantungan narkotika. Penyalahguna diancam dengan hukuman penjara, akan tetapi sebagian besar pecandu narkotika tidak melaporkan diri untuk sembuh juga diancam dengan hukuman pidana, namun upaya paksa dan penghukumannya berupa rehabilitasi. Hukuman rehabilitasi $=$ hukuman penjara. ${ }^{1}$

Sebagai acuan dalam tindakan yang dapat dikenakan oleh pecandu Narkotika sebagaimana dimaksud dalam Pasal 127 jo Pasal 55 jo Pasal 103 Undang-Undang Nomor 35 Tahun 2009 adalah Surat Edaran Mahkamah Agung Republik Indonesia Nomor 4 Tahun 2010, yang menyebutkan

kriteria pecandu narkoba yang dapat ditempatkan dalam lembaga rehabilitasi ${ }^{2}$ :

a. Kondisi tertangkap tangannya terdakwa saat ditangkap oleh Penyidik Polri maupun BNN

b. Berdasarkan butir a di atas, ditemukan barang bukti dalam 1 (satu) hari dengan rincian sebagai berikut:

1. 1 gram jenis Sabu-sabu

2. 2,4 gram / setara 8 butir jenis MDMA (ectasy)

3. 1,8 gram jenis Heroin

4. 1,8 gram jenis Kokain

5. 5 gram jenis Ganja

6. 5 gram jenis Daun Koka

7. 5 gram jenis Meskalin

8. 3 gram jenis Psilosybin

9. 2 gram jenis LSD (d-lysergic acid diethylamide)

10. 3 gram jenis PCP (Phencyclidine)

11. 1 gram jenis Fentanil

12. 0.5 gram jenis Metadon

13. 1,8 gram jenis Morfin

14. 0.96 gram jenis Petidine

15. 72 gram jenis Kodein

${ }^{1}$ Dr. Anang Iskandar, S.IK, SH, MH, Penegakan Hukum Narkotika (Rehabilitatif Terhadap Penyalah Guna Dan Pecandu, Represif Terhadap Pengedar) ( Jakarta: PT Alex Media Komputindo, 2019), hlm.6

${ }^{2}$ Lysa Angrayni, SH., MH, Dra. Hj. Yusliati, MA., Efektivitas Rehabilitasi Pecandu Narkotika Serta Pengaruhnya Terhadap Tingkat Kejahatan Di Indonesia ( Ponorogo: Uwais Inspirasi Indonesia, 2018), hlm. 6

(C) Author(s). This work is licensed under a Creative Commons Attribution 4.0 International License . Published by Postgraduate Program, Master of Laws, Faculty of Law, Universitas Sebelas Maret, Indonesia 


\section{32 gram jenis Bufrenofin}

c. Hasil Pengujian Laboratorium yang dinyatakan positif menggunakan narkoba yang dikeluarkan atas ketentuan permintaan penyidik.

d. Pentingnya surat keterangan kesehatan jiwa dari dokter jiwa atau psikiater yang ditunjuk oleh hakim.

e. Tidak terbuktinya keterlibatan dalam peredaran gelap narkotika.

Seirama dengan hal tersebut, Undang-Undang Nomor 35 Tahun 2009 berdasarkan Pancasila dan UUD NRI Tahun 1945 diselenggarakan berdasarkan asas kemanusiaan, pengayoman, keadilan, keamanan dan perlindungan. Dalam praktek sidang peradilan kenyataannya penerapan pidana dalam Undang-Undnag Nomor 35 Tahun 2009, khususnya Pasal 127 yakni untuk dirinya sendiri sebagai pemakai sangat bervariasi jenisnya, ada beberapa hakim yang menjerat pidana penjara dibarengi dengan pemberian rehabilitasi medis dan sosial, dan sebagaian hakim lagi ada yang menghukum dengan tindakan rehabilitasi tanpa disangkutkan dengan proses penjara dan ada pula yang hanya menjatuhkan pidana penjara saja yang kadang tanpa memperhatikan apakah pemakai tersebut sebagai pecandu. Sehingga putusan hakim tersebut belum mencerminkan nilai keadilan. ${ }^{3}$

Dewan Perwakilan Rakyat Daerah Indonesia (DPR RI) segera dapat memastikan adanya kepastian hukum dalam rancangan revisi Undang-undang Nomor 35 Tahun 2009 tentang Narkotika. Kepastian hukum itu penting agar penegakan UU Narkotika berjalan konsisten dan tidak ada pelaku penyalahguna tertentu yang mendapat perlakuan isitmewa. Selama ini yang terjadi ditengah-tengah masyarakat, bagi kalangan tertntu, misalnya artis yang kemudian menggunakan narkotika diberi (hukuman) rehabilitasi, sementara masyarakat yang ekonominya kurang atau kurang beruntung, tidak diberikan rehabilitasi. Ketentuan ini perlu diperjelas lagi dalam peraturan perundang-undangan.

Hal ini akan munculnya dampak pada permasalahan overcrowded lapas yang dapat menghambat kinerja Lapas dan Rutan dalam memberikan kelayakan kehidupan bagi pecandu narkotika didalam lapas dan rutan. Padahal hak atas kesehatan diatur dalam konstitusi Pasal $28 \mathrm{H}$ ayat (1) bahwa setiap orang berhak hidup sejahtera lahir dan batin, bertempat tinggal, dan mendapatkan lingkungan hidup yang baik dan sehat serta memperoleh pelayanan kesehatan yang merupakan pencerminan dari Hak Asasi Manusia, hal tersebut berdasarkan UU Kesehatan No 36 tahun 2009 tentang pemenuhan layanan kesehatan dilaksanakan dengan prinsip non-diskriminasi, dan permasalahan adiksi narkotika berdasarkan International Classification of Diseases and Health Problem (ICD-10) dari World Health Organization (WHO) yang merupakan penyakit psikis, ketergantungan dan/atau fisik bersifat kambuhan yang sangat membutuhkan pelayanan untuk menurunkan dampak buruk yang dihasilkan. ${ }^{4}$

${ }^{3}$ Dahlan, Problematika Keadilan dalam Penerapan Pidana terhadap Penyalah Guna Narkotika ( Sleman: Deepublish, 2017), hlm. 8

${ }^{4}$ Desmiati Ishak, Rofiqul Umam ahmad, Theo Yusuf MS, Jagalah Dirimu dan Keluargamu dari "Api" Narkoba (Jakarta: Pimpinan Pusat Gerakan Nasional Anti Narkoba Majelis Ulama Indonesia, 2020), hlm. 19

(c) Author(s). This work is licensed under a Creative Commons Attribution-NonCommercial-ShareAlike 4.0 International License. Published by Postgraduate Program, Master of Laws, Faculty of Law, Universitas Sebelas Maret, Indonesia 


\section{RESULTS \& DISCUSSION}

\section{Revisi pasal-pasal UU Narkotika akibat adanya penyimpangan dalam penerapan rehabilitasi}

Pedoman Penyelenggaraan Sarana Pelayanan Rehabilitasi Penyalahgunaan dan Ketergantungan napza telah diatur dan dijelaskan dalam KEPMENKES 996/MENKES/SK/VII/2002. Sarana pelayanan rehabilitasi adalah tempat yang digunakan untuk pemulihan dan pengembangan baik secara fisik, mental, sosial dan agama bagi seseorang yang ketergantungan narkoba.

Pecandu narkotika adalah manusia yang tetap memiliki hak yang sama dengan manusia lainnya. Pecandu juga memiliki hak asasi yang wajib dijunjung tinggi dan dihormati dalam kondisi apapun, karena dalam hal ini mereka memiliki hak asasi tersebut yang sudah melekat pada diri manusia itu sendiri sejak lahir. Ini berarti negara memiliki kewajiban dalam memberikan perlindungan hukum terhadap pengguna narktika, temasuk dalam pemenuhan hak-hak pengguna narkotika ditetapkan sebagai korban sehingga akan mendapatkan hak atas pembinaan dan rehabilitasi dari perspektif viktimologi. ${ }^{5}$

Pasal-pasal dalam UU Narkotika yang sering terjadi permasalahan dalam pemutusan sanksi bagi pecandu narkotika yaitu pasal 112, 114, dan pasal 127. Ketiga pasal tersebut mengandung ketidakjelasan rumusan yaitu Pasal 112 dan Pasal 127 UU Narkotika. Hal tersebut akan mengakibatkan para pengedar narkoba akan berlindung dimana seolah seolah mereka adalah pecandu narkoba.

Hal tersebut akan berdampak pada penjatuhan hukuman yang dinyatakan adanya ketidakadilan pada proses pelaksanaannya. Masyarakat baik itu pecandu narkoba maupun keluarga bersangkutan merasa dirugikan dengan berlakunya Pasal 111, 112, Pasal 114, serta Pasal 127 UU Narkotika, pasal-pasal tersebut memuat sanksi pidana bagi pelaku penyalahguna narkotika, yang bersangkutan dari adanya penerapan pasal tersebut menyebabkan hilangannya hak untuk direhabilitasi, padahal sebagai pengguna seharusnya ia diposisikan sebagai korban. Dari beberapa penelitian hukum ke lapangan para penyalahguna narkoba atau istilah lain pecandu narkba lebih banyak yang dipenjara ketimbang direhabilitasi. Institute for Criminal Justice Reform (ICJR) mencatat, dalam memperhatikan proses penerapan Rehabilitasi, para pecandu narkoba masih dominan dinilai sebagai pelaku kejahatan daripada mengutamakan kesehatan untuk penyembuhan ketergantungan terhadap narkotika tersebut.

Pernyataan pasal 111 ayat 1 UU Narkotika meyebutkan ${ }^{6}$ setiap orang yang tanpa hak atau melawan hukum menanam, memelihara, memiliki, menyimpan, menguasai, atau menyediakan narkotika Golongan I dalam bentuk tanaman, dipidana dengan pidana penjara paling singkat 4 tahun dan paling lama 12 tahun dan pidana denda paling sedikit Rp 800 juta dan paling banyak Rp 8 miliar. Sedangkan ketentuan pasal 112 ayat 1 menyatakan kemiripan dengan pasal 111 ayat 1 . Pada pasal 112 ayat 1 disebutkan ${ }^{7}$ setiap orang yang tanpa hak atau melawan hukum memiliki, menyimpan, menguasai, atau menyediakan

5 Dr. Darwis, M.Kes., Menghukum Atau Memulihkan Suatu Tinjauan Sosiologis Tentang Tindakan Terhadap Penyalahguna Nafza (Makassar: CV Sah Media, 2018), hlm. 11

${ }^{6}$ Bunyi Pasal 111 ayat (1) UU Narkotika

${ }^{7}$ Bunyi Pasal 112 ayat (1) UU Narkotika

(C) Author(s). This work is licensed under a Creative Commons Attribution 4.0 International License . Published by Postgraduate Program, Master of Laws, Faculty of Law, Universitas Sebelas Maret, Indonesia 
narkotika Golongan I bukan tanaman, dipidana dengan pidana penjara paling singkat 4 tahun dan paling lama 12 tahun dan pidana denda paling sedikit Rp 800 juta dan paling banyak Rp 8 miliar. Keduanya pasal tersebut adanya perbedaan dalam jenis narkotika, dengan pengelompokkan jenis yaitu, pasal 111 ayat 1 menangani jenis narkotika tanaman dan pasal 112 ayat 1 memayungi jenis narkotika bukan tanaman.

Lalu, Pasal 114 ayat (1) UU Narkotika menyatakan ${ }^{8}$ bahwa setiap orang yang tanpa hak atau melawan hukum menawarkan untuk dijual, menjual, membeli, menerima, menjadi perantara dalam jual beli, menukar, atau menyerahkan narkotika Golongan I, dipidana dengan pidana penjara seumur hidup atau pidana penjara paling singkat 5 (lima) tahun dan paling lama 20 (dua puluh) tahun dan pidana denda paling sedikit Rp. 1.000.000,000,00 (satu miliar rupiah) dan paling banyak (Rp 10.000.000.000,00 (sepuluh miliar rupiah).

Posisi dakwaan primair dihadapkan pada ketiga pasal tersebut. Bahwa dalam pasal tersebut terdapat unsur-unsur yang kompleks dan luas sehingga peluang menjerat pelaku semakin besar, persoalan ini membawa dampak meminimalisirnya kemungkinan bagi pengguna maupun pecandu narkoba diberikan dalam lembaga rehabilitasi medi s maupun sosial. ${ }^{9}$

Terjadi sedikit perbedaan dalam penerapan pasal 127 ayat (1) dalam dakwaan primer. Dalam pasal tersebut dinyatakan penyalahguna narkotika untuk golongan I bagi dirinya sendiri dipidana penjara paling lama 4 tahun. Sedangkan untuk golongan II bagi diri sendiri dipenjara paling lama 2 tahun dan narkotika golongan III bagi dirinya sendiri dipidana penjara paling lama 1 tahun. Akan tetapi dalam pasal 127 ayat (2) dalam memutus perkara sebagaimana dimaksud pada ayat (1), hakim wajib memperhatikan adanya ketentuan sebagaimana dimaksud dalam pasal 54, pasal 55, dan pasal 103 UU Narkotika dan dapat memberikan pedoman hakim untuk menempatkan pengguna narkotika ke lembaga rehabilitasi.

Beberapa contoh riset penelitian dalam 30 jenis putusan yang dilakukan oleh ICJR terkait tindak pidana narkotika yang menggunakan pasal 111 atau pasal 112 baik sebagai dakwaan pertama, primer, tunggal atau dakwaan kedua serta subsidair. Sebanyak 33 persen menggunakan pasal 127 dan 18 persen menggunakan pasal 114. ICJR mencatat ketika jaksa menggunakan pasal 127, mereka tetap mencantumkan pasal 111, 112 atau 114. Pasal 127 lebih banyak ditempatkan di posisi dakwaan subsidair. Ini menunjukkan bahwa jaksa masih ingin menjerat terdakwa dengan penggunaan pasal 111, 112 atau 114, karena dalam hal pembuktian lebih mudah untuk dibuktikan.

Sedangkan penjeratan pasal 111 atau 112 sebanyak 63 persen sebagai dakwaan primer. Sementara 37 persen mencantumkan pasal 114. Akan tetapi pasal 127 tidak ada satupun dicantumkan dalam putusan sebegai dakwaan pertama, hal tersebut berdampak pada vonis yang dijatuhkan hakim. Sehingga hanya 6 persen saja yang menjatuhkan hukuman rehabilitasi, seluruhnya tindakan rehabilitasi diberikan pada anak. ${ }^{10}$

\footnotetext{
${ }^{8}$ Bunyi Pasal 114 ayat (1) UU Narkotika

${ }^{9}$ Supriyadi Widodo Edyyono, Erasmus Napitupulu, Subhan Panjaitan, dkk, Memperkuat Revisi Undang-Undang Narkotika Indoneisa (Jakarta: Institute for Criminal Justice Reform, 2017), hlm. 21

${ }^{10}$ Husein Abdulsalam, Dilema Hukuman Rehabilitasi Narkoba. 2017. Diakes di https://tirto.id/dilemahukuman-rehabilitasi-narkoba-cvF8, pada tanggal 22 juni 2021 pukul 20.00
} 


\section{Problematika kasus tindak pidana narkotika terhadap penerapan pasal UU Narkotika}

Sejak ditetapkannya konvensi tunggal narkotika pada tahun 1961., negara Amerika sebagai pihak yang menginisiasi konvensi tersebut memberitahukan dunia untuk menanggulangi narkotika dengan strategi tidak pandang bulu, baik memenjarakan pengedar termasuk penyalah guna dan pecandu. Penanggulangan narkotika dilaksanakan dengan dimunculkannya "semangat" memenjarakan siapa saja yang terlibat masalah narkotika agar berdampak jera baik terhadap pelaku yang mengedarkan maupun kepada penggunanya.

Selama proses penanggulangan munculnya permasalahan yang tidak diduga sebelumnya, yaitu penjara dipenuhi oleh penjahat narkotika baik pengedar, penyalahguna dan adanya pecandu. Muncul permasalahan kesehatan, penyalah guna dan pecandu tetap tidak terpengaruh terhadap kesembuhan sakitnya (kecanduan), sehingga relap selama penjara, hal ini akan timbul residivisme setelah keluar dari penjara. Akhirnya, jumlah kasus penyalah guna meningkat pertumbuhan setiap tahunnya. ${ }^{11}$

Di Indonesia dalam penerapan rehabilitasi dari beberapa kasus memiliki penyimpangan, dibawah ini merupakan contoh dari menyimpangan penjeratan sanksi terhadap pecandu narkoba.

\section{P U T U S A N \\ Nomor 161/Pid-Sus/2016/PN.Plg}

DEMI KEADILAN BERDASARKAN KETUHANAN YANG MAHA ESA Pengadilan Negeri Palembang yang memeriksa dan mengadili perkara-perkara pidana biasa pada tingkat pertama telah menjatuhkan putusan sebagai berikut dalam perkara para terdakwa :

I.

$\begin{array}{ll}\text { Nama lengkap } & : \text { DEDI SANJAYA BIN SUKRI ; } \\ \text { Tempat lahir } & \text { : Palembang ; } \\ \text { Umur/ tgl lahir } & : \text { 31 tahun / 12 Juni 1984 } \\ \text { Jenis kelamin } & : \text { Laki-laki ; } \\ \text { Kebangsaan } & : \text { Indonesia ; } \\ \text { Tempat tinggal } & \text { : J1. Tansa Trisna Rt.15/02 No.-Kelurahan Srimulya } \\ & \text { Kecamatan Sematang Borang Palembang ; } \\ \text { Agama } & : \text { Islam ; } \\ \text { Pekerjaan } & \text { :Juru parkir ; }\end{array}$

II.

Nama lengkap : M.KIKI PRATAMA Bin IMRON ALS NANANG;

Tempat lahir : Palembang;

Umur/ tgl lahir : 24 tahun / 22 Agustus 1991;

Jenis kelamin : Laki-laki ;

Kebangsaan : Indonesia ;

11 DR. Anang Iskandar, S.IK, SH, MH, Politik Hukum Narkotika (Jakarta: PT Alex Media Komputindo, 2021), hlm. 5

(C) Author(s). This work is licensed under a Creative Commons Attribution 4.0 International License . Published by Postgraduate Program, Master of Laws, Faculty of Law, Universitas Sebelas Maret, Indonesia 


\section{Tempat tinggal : J1.Dr Isa Lr.Srikandi. Rt.31/06 No.- Kelurahan Duku Kecamatan IT-II Palembang; \\ Agama : Islam ; \\ Pekerjaan : Juru Parkir ;}

Para Terdakwa ditahan dalam tahanan rumah tahanan negara, masing - masing oleh:

- Penyidik Polri, sejak tanggal 27 Nopember 2015 sampai dengan tanggal 16 Desember 2015;

- Perpanjangan Penuntut Umum, sejak tanggal 17 Desember 2015 sampai dengan tanggal 25 Januari 2016;

- Penuntut Umum, sejak tanggal 19 Januari 2016 sampai dengan tanggal 7 Pebruari 2016;

- Majelis Hakim Pengadilan Negeri Klas I A Palembang, sejak tanggal 1 Februari 2016 sampai dengan tanggal 1 Maret 2016;

- Ketua Pengadilan Negeri Negeri Palembang, sejak tanggal 2 Maret 2016 sampai dengan tanggal 30 April 2016;

Para Terdakwa dipersidangan didampingi Penasehat Hukum dari POS BAKUM :

Pengadilan Negeri tersebut ;

Telah membaca berkas perkara :

Telah mendengar keterangan saksi-saksi dan keterangan para terdakwa dipersidangan ;

Telah membaca hasil laboratorium yang terlampir dalam berkas perkara ;

Penetapan Ketua Pengadilan Negeri Palembang No.161/PidSus/2016/PN.Plg, tanggal 1 Februari 2016 tentang penunjukan Majelis Hakim yang mengadili perkara ini

Penetapan Hakim Ketua Majelis Pengadilan Negeri Palembang Nomor 161/PidSus/2016/PN.Plg, tanggal 03 Pebruari 2016 tentang hari sidang pertama;

Surat Dakwaan Jaksa Penuntut Umum tertanggal 17 Pebruari 2016 yang dibacakan dipersidangan ;

Telah mendengar uraian tuntutan Penuntut Umum No.Reg.Perk : PDM-79/ Euh.2./2016 tertanggal 29 Januari 2016 yang pada pokoknya berbunyi sebagai berikut :

- MENYATAKAN TERDAKWA I. DEDI SANJAYA BIN SUKRI DAN TERDAKWA II. KIKI PRATAMA BIN IMRON ALIAS NANANG, BERSALAH TELAH MELAKUKAN TINDAK PIDANA SECARA TANPA HAK SELAKU PENYALAHGUNA NARKOTIKA GOLONGAN I BAGI DIRI SENDIRI DALAM DAKWAAN PASAL 127 Ayat (1)huruf a UU RI No.35 Thn 2009 tentang narkotika Jo Pasal $55 \mathrm{Ke}-1 \mathrm{KUHP}$.

- MENJATUHKAN SANKSI PIDANA PENJARA KEPADA TERDAKWA MASING MASING SELAMA 3 (tiga) TAHUN DIKURANGI SELAMA TERDAKWA BERADA DALAM TAHANAN SEMENTARA.

- MENYATAKAN BARANG BUKTI BERUPA

- 1(satu) paket kecil Narkotika jenis shabu - shabu degan berat netto 0,073 (nol koma nol tujuh tiga )gram dirampas untuk dimusnahkan.

- 1(satu)unit sepeda motor Honda beat Hitam BG.3513 AAR An NOVIYANTI dikembalikan pemiliknya An.NOVI YANTI 
- MENETAPKAN AGAR SUPAYA MEREKA PARA TERDAKWA MEMBAYAR BIAYA PERKARA MASING MASING SEBESAR RP.2.500,- ( Dua Ribu Lima Ratus Rupiah).

Menimbang, bahwa atas tuntutan Penuntut Umum tersebut, Penasehat Hukum para terdakwa kepada Majelis Hakim menyatakan atas tuntutan tersebut Penasehat Hukum para terdakwa tidak keberatan atas kwalifikasi pasal yang dibuktikan tapi keberatan atas lamanya tuntutan pidana yang dijatuhkan kepada terdakwa karena tuntutan tersebut terlalu berat dan tidak adil, dan mohon pertimbangan Majelis Hakim atas hal-hal sebagai berikut:

1. Bahwa para terdakwa bersikap sopan selama dipersidangan;

2. Bahwa para terdakwa mengaku belum pernah dihukum;

3. Bahwa para terdakwa menyesali perbuatanya dan berjanji tidak akan mengulangi perbuatanya lagi;

Menimbang bahwa dipersidangan Penuntut umum telah menyampaikan replik secara lisan pada pokoknya tetap pada tuntutanya, kemudian Penasehat Hukum para terdakwa secara lisan menyatakan tetap dengan pembelaanya semula;

Menimbang, bahwa terdakwa dihadapkan ke muka persidangan Pengadilan Negeri Palembang oleh Penuntut Umum dengan surat Dakwaan No. PDM-79/PEuh.2/01/2016 tertanggal 29 Januari 2016 adalah sebagai berikut ;

\section{PERTAMA :}

Bahwa ia Terdakwa I. DEDI SANJAYA BIN SUKRI, bersama dengan Terdakwa II. KIKI PRATAMA BIN IMRON ALS NANANG, Pada hari Kamis tanggal 26 November 2015 sekira jam 10.30 wib atau pada suatu waktu dalam bulan Nopember 2015 bertempat di Jalan Segaran tepatnya depan Lrg.Kemas Kec.IT-II Palembang atau disuatu tempat yang masih termasuk dalam daerah hukum Pengadilan Negeri Palembang yang berwenang memeriksa dan mengadili perkara ini, " Percobaan atau Permupakatan Jahat untuk melakukan Tindak Pidana Narkotika, yang tanpa hak atau melawan hukum, Menawarkan untuk dijual, Menjual, Membeli, Menerima, Menjadi Perantara dalam Jual Beli, Menukar atau Menyerahkan Narkotika golongan I, berupa 1 (satu) paket kecil Narkotika jenis shabu dengan berat netto 0,073 (nol koma nol tujuh puluh tiga) gram, (berdasarkan hasil penimbangan Petugas Laboratorium Forensik POLRI Cabang Palembang), Perbuatan mana dilakukan terdakwa dengan cara - cara sebagai berikut :

Berawal Pada Hari Kamis tanggal 26 November 2015 sekitar jam 09.00 wib Terdakwa I. DEDI SANJAYA BIN SUKRI menemui Terdakwa II. KIKI PRATAMA BIN IMRON ALS NANANG diparkiran GOLF, Kemudian langsung Jalan dengan menggunakan sepeda motor Honda beat Warna Hitam BG 3513 AAR yang membawa sepeda motor saat itu Terdakwa I. DEDI SANJAYA BIN SUKRI sedangkan Terdakwa II. KIKI PRATAMA BIN IMRON ALS NANANG di bonceng, kemudian terdakwa I. DEDI SANJAYA BIN SUKRI dan Terdakwa II. KIKI PRATAMA BIN IMRON ALS NANANG bersepakat untuk menggunakan Narkotika jenis sabu selanjutnya pergi ke daerah 13 Ilir Palembang, sekitar jam 10.00 wib sampai di 13 Ilir, Lalu terdakwa I. DEDI SANJAYA BIN SUKRI memberikan uang Rp.150.000,- kepada Terdakwa II. M.KIKY PRATAMA BIN IMRON

(C) Author(s). This work is licensed under a Creative Commons Attribution 4.0 International License . Published by Postgraduate Program, Master of Laws, Faculty of Law, Universitas Sebelas Maret, Indonesia 
Als NANANG karena Terdakwa II. KIKI PRATAMA BIN IMRON ALS NANANG tidak mempunyai uang maka terdakwa II. KIKI PRATAMA BIN IMRON ALS NANANG memakai uang terdakwa I. DEDI SANJAYA BIN SUKRI terlebih dahulu, setelah menerima uang Rp.150.000,- (seratus lima puluh ribu rupiah) dari terdakwa I.DEDI SANJAYA BIN SUKRI, selanjutnya langsung pergi berjalan kaki masuk kedalam lorong sedangkan Terdakwa DEDI SANJAYA BIN SUKRI menunggu diatas sepeda motor yang dikemudikan oleh terdakwa II. KIKI PRATAMA BIN IMRON ALS NANANG distop oleh saksi Bripka. Prayitno,SH dan Brigadir. Yuriko, SE, SMi dan rekan lain dari Sat Narkoba Polresta Palembang, langsung mengamankan Terdakwa I. DEDI SANJAYA BIN SUKRI dan Terdakwa II. KIKI PRATAMA BIN IMRON ALS NANANG, Kemudian dilakukan penggeledahan ditemukan 1 (satu) paket kecil Narkotika jenis sabu didalam kantong keresek hitam bungkus nasi gemuk yang tergantung digantungan sepeda motor.

Bahwa Terdakwa I. DEDI SANJAYA BIN SUKRI dan Terdakwa II. KIKI PRATAMA BIN IMRON ALS NANANG mengakui bahwa 1 (satu) paket kecil Narkotika jenis sabu - sabu tersebut baru di beli di 13 Ilir Palembang dari seorang laki-laki yang tidak diketahui namanya yang mana rencananya Narkotika jenis sabu-sabu tersebut akan di pergunakan bersama, Mengetahui Terdakwa I. DEDI SANJAYA BIN SUKRI dan Terdakwa II. KIKI PRATAMA BIN IMRON ALS NANANG Memiliki, Menyimpan atau Menguasai 1 (satu) paket Narkotika jenis sabu-sabu tersebut, tidak ada izin dari yang berwenang, Kemudian beserta barang bukti di bawah ke Polresta Palembang untuk pemeriksaan lebih lanjut. Bahwa berdasarkan Hasil Pemeriksaan Laboratoris Kriminalitis No.Lab : 3009/ NNF/2015, setelah dilakukan pemeriksaan secara laboratoris kriminalistik disimpulkan bahwa barang bukti berupa : Kristal - kristal putih pada tabel 01, urine pada tabel 02 milik tersangka an. KIKI PRATAMA BIN IMRON ALS NANANG mengandung Metamfetamina yang terdaftar sebagai Golongan I (satu) Nomor urut 61 pada lampiran Undang-undang Republik Indonesia No.35 Tahun 2009 tentang Narkotika. Urine pada tabel 02 milik tersangka DEDI SANJAYA BIN SUKRI tidak mengandung Narkotika.

Bahwa sekitar 15 (lima belas) menit kemudian Terdakwa II. M. KIKY PRATAMA BIN IMRON Als NANANG keluar dari dalam lorong kembali menemui terdakwa I. dan menyerahkan 1 (satu) paket kecil Narkotika jenis sabu lalu di simpan didalam kantong keresek hitam bungkus nasi gemuk, Kemudian Terdakwa I. DEDI SANJAYA BIN SUKRI dan Terdakwa II. KIKI PRATAMA BIN IMRON ALS NANANG pergi, saat melintas di Jalan Segaran tepatnya depan Lrg. Kemas Kec. IT-II Palembang, Sepeda motor yang dikemudikan oleh terdakwa II. KIKI PRATAMA BIN IMRON ALS NANANG distop oleh saksi Bripka. Prayitno,SH dan Brigadir. Yuriko, SE, SMi dan rekan lain dari Sat Narkoba Polresta Palembang, langsung mengamankan Terdakwa I. DEDI SANJAYA BIN SUKRI dan Terdakwa II. KIKI PRATAMA BIN IMRON ALS NANANG, Kemudian dilakukan penggeledahan ditemukan 1 (satu) paket kecil Narkotika jenis sabu didalam kantong keresek hitam bungkus nasi gemuk yang tergantung digantungan sepeda motor.

Bahwa Terdakwa I. DEDI SANJAYA BIN SUKRI dan Terdakwa II. KIKI PRATAMA BIN IMRON ALS NANANG mengakui bahwa 1 (satu) paket kecil Narkotika jenis sabu - sabu tersebut baru di beli di 13 Ilir Palembang dari seorang laki-laki yang tidak diketahui namanya yang mana rencananya Narkotika jenis sabu-sabu tersebut akan di pergunakan bersama, Mengetahui Terdakwa I. DEDI SANJAYA BIN SUKRI dan Terdakwa II. KIKI PRATAMA BIN IMRON ALS NANANG Memiliki, Menyimpan atau

(C) Author(s). This work is licensed under a Creative Commons Attribution-NonCommercial-ShareAlike 4.0 International License. Published by Postgraduate Program, Master of Laws, Faculty of Law, Universitas Sebelas Maret, Indonesia 
Menguasai 1 (satu) paket Narkotika jenis sabu-sabu tersebut, tidak ada izin dari yang berwenang, Kemudian beserta barang bukti di bawah ke Polresta Palembang untuk pemeriksaan lebih lanjut.

Bahwa berdasarkan Hasil Pemeriksaan Laboratoris Kriminalitis No.Lab : 3009/ NNF/2015, setelah dilakukan pemeriksaan secara laboratoris kriminalistik disimpulkan bahwa barang bukti berupa :

Kristal - kristal putih pada tabel 01, urine pada tabel 02 milik tersangka an. KIKI PRATAMA BIN IMRON ALS NANANG mengandung Metamfetamina yang terdaftar sebagai Golongan I (satu) Nomor urut 61 pada lampiran Undang-undang Republik Indonesia No.35 Tahun 2009 tentang Narkotika.

Urine pada tabel 02 milik tersangka DEDI SANJAYA BIN SUKRI tidak mengandung sediaan Narkotika.

Perbuatan terdakwa sebagaimana diatur dan diancam pidana dalam pasal 132 ayat (1) UU RI No. 35 tahun 2009 Tentang Narkotika Jo Pasal 114 ayat (1) UU RI No 35 Tahun 2009 tentang Narkotika.

\section{ATAU KEDUA :}

Bahwa ia Terdakwa I. DEDI SANJAYA BIN SUKRI, bersama dengan Terdakwa II. KIKI PRATAMA BIN IMRON ALS NANANG, Pada hari Kamis tanggal 26 November 2015 sekira jam 10.30 wib atau pada suatu waktu dalam bulan Nopember 2015 bertempat di Jalan Segaran tepatnya depan Lrg.Kemas Kec.IT-II Palembang atau disuatu tempat yang masih termasuk dalam daerah hukum Pengadilan Negeri Palembang yang berwenang memeriksa dan mengadili perkara ini, " Percobaan atau Permupakatan Jahat untuk melakukan Tindak Pidana Narkotika, yang tanpa hak atau melawan hukum, memiliki, menyimpan, menguasai, atau menyediakan Narkotika Golongan I bukan tanaman, berupa 1 (satu) paket kecil Narkotika jenis shabu dengan berat netto 0,073 (nol koma nol tujuh puluh tiga) gram, (berdasarkan hasil penimbangan Petugas Laboratorium Forensik POLRI Cabang Palembang), (berdasarkan hasil penimbangan Petugas Laboratorium Forensik POLRI Cabang Palembang), Perbuatan mana dilakukan terdakwa dengan cara - cara sebagai berikut

Berawal Pada Hari Kamis tanggal 26 November 2015 sekitar jam 09.00 wib Terdakwa I. DEDI SANJAYA BIN SUKRI menemui Terdakwa II. KIKI PRATAMA BIN IMRON ALS NANANG diparkiran GOLF, Kemudian langsung Jalan dengan menggunakan sepeda motor Honda beat Warna Hitam BG 3513 AAR yang membawa sepeda motor saat itu Terdakwa I. DEDI SANJAYA BIN SUKRI sedangkan Terdakwa II. KIKI PRATAMA BIN IMRON ALS NANANG di bonceng, kemudian terdakwa I. DEDI SANJAYA

BIN SUKRI dan Terdakwa II. KIKI PRATAMA BIN IMRON ALS NANANG bersepakat untuk menggunakan Narkotika jenis sabu selanjutnya pergi ke daerah 13 Ilir Palembang, sekitar jam 10.00 wib sampai di 13 Ilir, Lalu terdakwa I. DEDI SANJAYA BIN SUKRI memberikan uang Rp.150.000,- kepada Terdakwa II. M.KIKY PRATAMA BIN IMRON Als NANANG karena Terdakwa II. KIKI PRATAMA BIN IMRON ALS NANANG tidak mempunyai uang maka terdakwa II. KIKI PRATAMA BIN IMRON ALS NANANG memakai uang terdakwa I. DEDI SANJAYA BIN SUKRI terlebih dahulu, setelah menerima uang Rp.150.000,- (seratus lima puluh ribu rupiah) dari terdakwa I.DEDI

(C) Author(s). This work is licensed under a Creative Commons Attribution 4.0 International License . Published by Postgraduate Program, Master of Laws, Faculty of Law, Universitas Sebelas Maret, Indonesia 
SANJAYA BIN SUKRI, selanjutnya langsung pergi berjalan kaki masuk kedalam lorong sedangkan Terdakwa DEDI SANJAYA BIN SUKRI menunggu diatas sepeda motor.

Bahwa sekitar 15 (lima belas) menit kemudian Terdakwa II. M. KIKY PRATAMA BIN IMRON Als NANANG keluar dari dalam lorong kembali menemui terdakwa I. dan menyerahkan 1 (satu) paket kecil Narkotika jenis sabu lalu di simpan didalam kantong keresek hitam bungkus nasi gemuk, Kemudian Terdakwa I. DEDI SANJAYA BIN SUKRI dan Terdakwa II. KIKI PRATAMA BIN IMRON ALS NANANG pergi, saat melintas di Jalan Segaran tepatnya depan Lrg. Kemas Kec. IT-II Palembang, Sepeda motor yang dikemudikan oleh terdakwa II. KIKI PRATAMA BIN IMRON ALS NANANG distop oleh saksi Bripka. Prayitno,SH dan Brigadir. Yuriko, SE, SMi dan rekan lain dari Sat Narkoba Polresta Palembang, langsung mengamankan Terdakwa I. DEDI SANJAYA BIN SUKRI dan Terdakwa II. KIKI PRATAMA BIN IMRON ALS NANANG, Kemudian dilakukan penggeledahan ditemukan 1 (satu) paket kecil Narkotika jenis sabu didalam kantong keresek hitam bungkus nasi gemuk yang tergantung digantungan sepeda motor.

Bahwa Terdakwa I. DEDI SANJAYA BIN SUKRI dan Terdakwa II. KIKI PRATAMA BIN IMRON ALS NANANG mengakui bahwa 1 (satu) paket kecil Narkotika jenis sabu - sabu tersebut baru di beli di 13 Ilir Palembang dari seorang laki-laki yang tidak diketahui namanya yang mana rencananya Narkotika jenis sabu-sabu tersebut akan di pergunakan bersama, Mengetahui Terdakwa I. DEDI SANJAYA BIN SUKRI dan Terdakwa II. KIKI PRATAMA BIN IMRON ALS NANANG Memiliki, Menyimpan atau Menguasai 1 (satu) paket Narkotika jenis sabu-sabu tersebut, tidak ada izin dari yang berwenang, Kemudian beserta barang bukti di bawah ke Polresta Palembang untuk pemeriksaan lebih lanjut

Bahwa berdasarkan Hasil Pemeriksaan Laboratoris Kriminalitis No.Lab : 3009/ NNF/2015, setelah dilakukan pemeriksaan secara laboratoris kriminalistik disimpulkan bahwa barang bukti berupa :

Kristal - kristal putih pada tabel 01, urine pada tabel 02 milik tersangka an. KIKI PRATAMA BIN IMRON ALS NANANG mengandung Metamfetamina yang terdaftar sebagai Golongan I (satu) Nomor urut 61 pada lampiran Undang-undang Republik Indonesia No.35 Tahun 2009 tentang Narkotika.

Urine pada tabel 02 milik tersangka DEDI SANJAYA BIN SUKRI tidak mengandung sediaan Narkotika.

Perbuatan terdakwa sebagaimana diatur dan diancam pidana dalam pasal 132 ayat (1) UU RI No.35 tahun 2009 Tentang Narkotika Jo Pasal 112 ayat (1) UU RI No 35 Tahun 2009 tentang Narkotika.

Menimbang, bahwa atas dakwaan Penuntut Umum tersebut para terdakwa melalui Penasehat Hukum para terdakwa menyatakan sudah mengerti dan memahami maksudnya serta tidak mengajukan eksepsi;

Menimbang, bahwa untuk membuktikan dakwaannya, Penuntut Umum mengajukan saksisaksi sebagai berikut :

1. Saksi Bripka Prayitno, SH Bin Wasik, dibawah sumpah dimuka persidangan memberikan keterangan pada pokoknya sebagai berikut :

(c) Author(s). This work is licensed under a Creative Commons Attribution-NonCommercial-ShareAlike 4.0 International License. Published by Postgraduate Program, Master of Laws, Faculty of Law, Universitas Sebelas Maret, Indonesia 
- Bahwa pada Kamis tanggal 26 November 2015 sekitar jam 10.30 WIB di Jalan Segaran depan Lorong Kemas Kecamatan IT.II Palembang; telah terjadi penangkapan terhadap para terdakwa Dedi Sanjaya Bin Sukri dan M.Kiki Pratama Bin Imron Als Nanang

- Bahwa pada saat penangkapan ditemukan 1 (satu) paket kecil yang dibungkus dengan plastic klip bening, dari dalam kantong keresek hitam bungkus nasi gemuk yang tergantung digantungan sepeda motor yang dikemudikan oleh terdakwa.

- Bahwa sebelum penangkapan saksi bersama rekan-rekan melakukan penyidikan lebih dulu, melihat dari kejauhan, melihat para terdakwa mengendarai sepeda motor Honda Beat Warna Hitam BG.3513 AR masuk kedalam lorong yang ada dipinggiran DAM, dikarenakan merasa curiga kedua terdakwa berjalan dengan motornya, lalu saksi bersama rekannya membututi dan ketika tepat dijalan segaran depan lorong kemas, saksi menyuruh menghentikan sepeda motornya dan digeledah tidak mendapatkan narkotika jenis apapun, kemudian saksi menggeledah kantong kresek hitam yang digantunga sepeda motor berisikan nasi gemuk yang didalamnya ditemukan1 (satu) paket kecil shabu

- Bahwa 1 (satu) paket shabu shabu tersebut dibeli oleh para terdakwa seharga Rp. 150.000,- (dua ratus ribu rupiah);

- Bahwa shabu shabu tersebut ditanyakan kepada para terdakwa untuk dipakai bersama;

Atas keterangan dari saksi tersebut, terdakwa tidak berkeberatan dan membenarkannya;

2. Saksi Birgadir A.Yurico, SE Msi Bin H.Amri Rasyid., dibawah sumpah didepan persidangan memberikan keterangan pada pokoknya sebagai berikut :

- Bahwa pada Kamis tanggal 26 November 2015 sekitar jam 10.30 WIB di Jalan Segaran depan Lorong Kemas Kecamatan IT.II Palembang telah terjadi penangkapan terhadap para terdakwa Dedi Sanjaya Bin Sukri dan M.Kiki Pratama Bin Imron Als Nanang;

- Bahwa pada saat penangkapan ditemukan 1 (satu) paket kecil yang dibungkus dengan plastic klip bening, dari dalam kantong keresek hitam bungkus nasi gemuk yang tergantung digantungan sepeda motor yang dikemudikan oleh terdakwa.

- Bahwa sebelum penangkapan saksi bersama rekan-rekan melakukan penyidikan lebih dulu, melihat dari kejauhan, melihat para terdakwa mengendarai sepeda motor Honda Beat Warna Hitam BG.3513 AR masuk kedalam lorong yang ada dipinggiran DAM, dikarenakan merasa curiga kedua terdakwa berjalan dengan motornya, lalu saksi bersama rekannya membututi dan ketika tepat dijalan segaran depan lorong kemas, saksi menyuruh menghentikan sepeda motornya dan digeledah tidak mendapatkan narkotika jenis apapun, kemudian saksi menggeledah kantong kresek hitam yang digantunga sepeda motor berisikan nasi gemuk yang didalamnya ditemukan1 (satu) paket kecil shabu.

- Bahwa 1 (satu) paket shabu shabu tersebut dibeli oleh para terdakwa seharga Rp. 150.000,- (dua ratus ribu rupiah);

- Bahwa shabu shabu tersebut ditanyakan kepada para terdakwa untuk dipakai bersama

Atas keterangan saksi tersebut terdakwa tidak berkeberatan dan membenarkannya;

(C) Author(s). This work is licensed under a Creative Commons Attribution 4.0 International License . Published by Postgraduate Program, Master of Laws, Faculty of Law, Universitas Sebelas Maret, Indonesia 
3. Saksi Biriptu M.Cahaya Ramadan, SH Bin Syamsurizal., dibawah sumpah didepan persidangan memberikan keterangan pada pokoknya sebagai berikut :

- Bahwa pada Kamis tanggal 26 November 2015 sekitar jam 10.30 WIB di Jalan Segaran depan Lorong Kemas Kecamatan IT.II Palembang telah terjadi penangkapan terhadap para terdakwa Dedi Sanjaya Bin Sukri dan M.Kiki Pratama Bin Imron Als Nanang;

- Bahwa pada saat penangkapan ditemukan 1 (satu) paket kecil yang dibungkus dengan plastic klip bening, dari dalam kantong keresek hitam bungkus nasi gemuk yang tergantung digantungan sepeda motor yang dikemudikan oleh terdakwa.

- Bahwa sebelum penangkapan saksi bersama rekan-rekan melakukan penyidikan lebih dulu, melihat dari kejauhan, melihat para terdakwa mengendarai sepeda motor Honda Beat Warna Hitam BG.3513 AR masuk kedalam lorong yang ada dipinggiran DAM, dikarenakan merasa curiga kedua terdakwa berjalan dengan motornya, lalu saksi bersama rekannya membututi dan ketika tepat dijalan segaran depan lorong kemas, saksi menyuruh menghentikan sepeda motornya dan digeledah tidak mendapatkan narkotika jenis apapun, kemudian saksi menggeledah kantong kresek hitam yang digantunga sepeda motor berisikan nasi gemuk yang didalamnya ditemukan1 (satu) paket kecil shabu.

- Bahwa 1 (satu) paket shabu shabu tersebut dibeli oleh para terdakwa seharga Rp. 150.000,- (dua ratus ribu rupiah);

- Bahwa shabu shabu tersebut ditanyakan kepada para terdakwa untuk dipakai bersama.

Atas keterangan saksi tersebut terdakwa tidak berkeberatan dan membenarkannya;

Menimbang, bahwa selanjutnya dimuka persidangan telah pula didengar keterangan terdakwa Muhammad Iqbal Bin Herman yang pada pokoknya sebagai berikut :

Menimbang, bahwa selanjutnya dimuka persidangan telah pula didengar keterangan terdakwa Dedy Sanjaya Bin Sukri yang pada pokoknya sebagai berikut:

- Bahwa benar pada Kamis tanggal 26 November 2015 sekitar jam 10.30 WIB di Jalan Segaran depan Lorong Kemas Kecamatan IT.II Palembang, petugas kepolisian telah meakukan penangkapan terhadap para terdakwa

- Bahwa pada saat penangkapan ditemukan 1 (satu) paket kecil yang dibungkus dengan plastic klip bening, dari dalam kantong keresek hitam bungkus nasi gemuk yang tergantung digantungan sepeda motor yang dikemudikan oleh terdakwa.

- Bahwa sebelum para terdakwa mengendarai sepeda motor Honda Beat Warna Hitam BG.3513 AR masuk kedalam lorong yang ada dipinggiran DAM, kemudian para terdakwa disuruh petugas menghentikan sepeda motornya dan digeledah tidak mendapatkan narkotika jenis apapun, kemudian kantong kresek hitam yang digantungan sepeda motor digeledah dan dibuka berisikan nasi gemuk yang didalamnya ditemukan1 (satu) paket kecil shabu.

- Bahwa 1 (satu) paket shabu shabu tersebut dibeli oleh para terdakwa seharga Rp. 150.000,- (dua ratus ribu rupiah);

- Bahwa shabu shabu tersebut ditanyakan kepada para terdakwa untuk dipakai bersama

Menimbang, bahwa barang bukti didalam persidangan tersebut berupa 1 (satu) paket kecil jenis shabu dibungkus plastic klip bening dibenarkan oleh terdakwa; 
Menimbang, bahwa berdasarkan keterangan para saksi dan terdakwa serta barang bukti dan hasil pemeriksaan secara laboratoris atas barang bukti maka diperoleh fakta-fakta hukum dipersidangan,yaitu :

- Bahwa pada Kamis tanggal 26 November 2015 sekitar jam 10.30 WIB di Jalan Segaran depan Lorong Kemas Kecamatan IT.II Palembang telah terjadi penangkapan terhadap para terdakwa Dedi Sanjaya Bin Sukri dan M.Kiki Pratama Bin Imron Als Nanang;

- Bahwa pada saat penangkapan ditemukan 1 (satu) paket kecil yang dibungkus dengan plastic klip bening, dari dalam kantong keresek hitam bungkus nasi gemuk yang tergantung digantungan sepeda motor yang dikemudikan oleh terdakwa.

- Bahwa sebelum penangkapan saksi bersama rekan-rekan melakukan penyidikan lebih dulu, melihat dari kejauhan, melihat para terdakwa mengendarai sepeda motor Honda Beat Warna Hitam BG.3513 AR masuk kedalam lorong yang ada dipinggiran DAM, dikarenakan merasa curiga kedua terdakwa berjalan dengan motornya, lalu saksi bersama rekannya membututi dan ketika tepat dijalan segaran depan lorong kemas, saksi menyuruh menghentikan sepeda motornya dan digeledah tidak mendapatkan narkotika jenis apapun, kemudian saksi menggeledah kantong kresek hitam yang digantunga sepeda motor berisikan nasi gemuk yang didalamnya ditemukan1 (satu) paket kecil shabu.

- Bahwa 1 (satu) paket shabu shabu tersebut dibeli oleh para terdakwa seharga Rp. 150.000,- (dua ratus ribu rupiah);

- Bahwa shabu shabu tersebut ditanyakan kepada para terdakwa untuk dipakai bersama

Menimbang, bahwa selanjutnya Majelis Hakim akan mempertimbangkan, apakah berdasarkan fakta-fakta hukum tersebut diatas, terdakwa dapat dinyatakan telah melakukan tindak pidana yang didakwakan kepadanya; Menimbang, bahwa terdakwa telah didakwaan oleh Penuntut Umum dengan Dakwaan Kesatu pasal 114(1) UU-RI No.35 / 2009 Kedua melanggar Pasal 112 (1) UU RI No.35 tahun 2009 tentang Narkotika Jo Pasal 132 UU RI Nomor 35 tahun 2009 atau Kedua melanggar Pasal 127 ayat (1) UU RI No.35 tahun 2009 Jo Pasal 55 ayat (1) ke-1 KUHP;

Menimbang, bahwa karena dakwaan disusun secara Alternatif, maka Majelis Hakim akan mempertimbangkan perbuatan terdakwa pada salah satu dakwaan yang sesuai dengan fakta yang terungkap dalam peresidangan yaitu pada dakwaan Kedua melanggar Pasal 127 ayat (1) huruf a UU RI No.35 tahun 2009 Jo Pasal 55 ayat (1) ke-1 KUHP tentang Narkotika yang unsur-unsurnya sebagai berikut :

1. Setiap Orang ;

2. Turut serta melakukan penyalah guna Narkotika Golongan I bagi diri sendiri;

Menimbang, bahwa terhadap unsur-unsur tersebut Majelis Hakim mempertimbangkan sebagai berikut: Ad.1. Unsur "Setiap Orang"

Menimbang, bahwa Unsur "setiap orang" adalah menunjuk pada subyek hukum (natuurlijk persoon) yakni orang yang dihadapkan dipersidangan sebagai terdakwa dan secara hukum mampu mempertanggung jawabkan seluruh perbuatannya; Selanjutnya berdasarkan keterangan para saksi dan keterangan terdakwa ternyata benar Terdakwa Dedy

(C) Author(s). This work is licensed under a Creative Commons Attribution 4.0 International License . Published by Postgraduate Program, Master of Laws, Faculty of Law, Universitas Sebelas Maret, Indonesia 
Sanjaya Bin Sukri dan terdakwa Kiki Pratama Bin Imron Als Nanang yang dihadapkan dipersidangan perkara ini adalah Terdakwa yang dimaksudkan dalam surat dakwaan Penuntut Umum serta terdakwa dalam keadaan sehat jasmani dan rohani sehingga dapat mempertanggung jawabkan perbuatannya menurut hukum.

Dengan demikian "unsur setiap orang" ini telah terbukti secara sah menurut hukum. Ad.2. Unsur "turut serta melakukan penyalah guna Narkotika Golongan I bagi diri sendiri"

Menimbang, Berdasarakan fakta-fakta dipersidangan dari keterangan saksi-saksi dan keterangan terdakwa sendiri serta dihubungkan dengan alat bukti yang ada didepan persidangan, bahwa pada Kamis tanggal 26 November 2015 sekitar jam 10.30 WIB di Jalan Segaran depan Lorong Kemas Kecamatan IT.II Palembang telah terjadi penangkapan terhadap para terdakwa Dedi Sanjaya Bin Sukri dan M.Kiki Pratama Bin Imron Als Nanang pada saat penangkapan ditemukan 1 (satu) paket kecil yang dibungkus dengan plastic klip bening, dari dalam kantong keresek hitam bungkus nasi gemuk yang tergantung digantungan sepeda motor yang dikemudikan oleh terdakwa jeni sepeda motor Honda Beat Warna Hitam BG.3513 AR masuk kedalam lorong yang ada dipinggiran DAM, dikarenakan merasa curiga kedua terdakwa berjalan dengan motornya, lalu saksi bersama rekannya membututi dan ketika tepat dijalan segaran depan lorong kemas, saksi menyuruh menghentikan sepeda motornya dan digeledah tidak mendapatkan narkotika jenis apapun, kemudian saksi menggeledah kantong kresek hitam yang digantunga sepeda motor berisikan nasi gemuk yang didalamnya ditemukan1 (satu) paket kecil shabu, 1 (satu) paket shabu shabu tersebut dibeli oleh para terdakwa seharga Rp. 150.000,- (dua ratus ribu rupiah); untuk dipakai para terdakwa cara membeli dengan harga Rp. 150.000,- (seratus lima ribu ribu rupiah) yang rencananya akan digunakan oleh para terdakwa secara bersamasama;

Dengan demikian "turut serta melakukan penyalah guna Narkotika Golongan I bagi diri sendiri” ini telah terbukti secara sah menurut hukum. Menimbang, bahwa sebagaimana majelis hakim pertimbangkan diatas semua unsur dalam dakwaan kesatu tersebut telah terpenuhi, maka dengan demikian dakwaan Penuntut Umum tersebut dinyatakan terbukti secara sah dan meyakinkan dengan kualifikasi tindak pidana sebagaimana tersebut dalam amar putusan ini ; Menimbang, bahwa selama dalam persidangan tidak ditemukan alasan pemaaf atau pembenar pada diri para terdakwa sehingga para terdakwa dinyatakan bersalah dan dipidana ; Menimbang, bahwa sebelum Majelis menjatuhkan pidana terhadap para terdakwa, dipertimbangkan hal-hal yang memberatkan dan meringankan para terdakwa; Hal-hal yang memberatkan : - Bahwa perbuatan para terdakwa tidak mendukung program pemerintah di dalam memberantas peredaran / penyalahgunaan Narkotika; Hal-hal yang meringankan : - Bahwa Para Terdakwa mengakui perbuatanya

Bahwa Para Terdakwa sopan dalam persidangan; - Bahwa Para Terdakwa menyesali perbuatanya dan berjanji tidak mengulanginya; - Bahwa para terdakwa belum pernah dihukum; Menimbang, bahwa dengan mempertimbangkan hal-hal tersebut diatas, maka pidana yang dijatuhkan terhadap para terdakwa telah dirasa tepat dan adil; Menimbang, bahwa oleh karena para terdakwa dalam perkara ini telah menjalani masa penangkapan dan penahanan rutan, maka berdasarkan pasal 22 
Menimbang, bahwa barang bukti berupa 1 (satu) buah paket Narkotika jenis shabu shabu yang dibungkus plastik bening didapat para terdakwa dengan cara membeli dengan harga Rp. 150.000,- (seratus lima ribu ribu rupiah) yang rencananya akan digunakan oleh para terdakwa secara bersama-sama;

Menimbang, bahwa sebagaimana majelis hakim pertimbangkan diatas semua unsur dalam dakwaan kesatu tersebut telah terpenuhi, maka dengan demikian dakwaan Penuntut Umum tersebut dinyatakan terbukti secara sah dan meyakinkan dengan kualifikasi tindak pidana sebagaimana tersebut dalam amar putusan ini;

Menimbang, bahwa selama dalam persidangan tidak ditemukan alasan pemaaf atau pembenar pada diri para terdakwa sehingga para terdakwa dinyatakan bersalah dan dipidana;

Menimbang, bahwa sebelum Majelis menjatuhkan pidana terhadap para terdakwa, dipertimbangkan hal-hal yang memberatkan dan meringankan para terdakwa;

Hal-hal yang memberatkan :

- Bahwa perbuatan para terdakwa tidak mendukung program pemerintah di dalam memberantas peredaran / penyalahgunaan Narkotika; Hal-hal yang meringankan :

- Bahwa Para Terdakwa mengakui perbuatanya

- Bahwa Para Terdakwa sopan dalam persidangan;

- Bahwa Para Terdakwa menyesali perbuatanya dan berjanji tidak mengulanginya;

- Bahwa para terdakwa belum pernah dihukum;

Menimbang, bahwa dengan mempertimbangkan hal-hal tersebut diatas, maka pidana yang dijatuhkan terhadap para terdakwa telah dirasa tepat dan adil;

Menimbang, bahwa oleh karena para terdakwa dalam perkara ini telah menjalani masa penangkapan dan penahanan rutan, maka berdasarkan pasal 22 ayat (4) KUHAP masa penangkapan dan penahanan yang telah dijalani terdakwa tersebut dikurangkan seluruhnya dari pidana yang dijatuhkan dengan perintah agar para terdakwa tetap berada dalam tahanan;

Menimbang, bahwa terhadap barang bukti berupa 1 (satu) paket kecil shabu dibungkus plastic klip transparan dengan berat 0,057 (nol koma nol lima tujuh) gram (sisa Labfor), ditetapkanr statusnya sebagaimana tersebut dalam amar putusan ini;

Menimbang, bahwa oleh karena terdakwa dinyatakan bersalah dan dijatuhi pidana, maka sesuai dengan ketentuan pasal 222 ayat 1 KUHAP kepada para terdakwa dibebani untuk membayar biaya perkara yang besarnya sebagaimana tersebut dalam amar putusan ini;

Mengingat Pasal 127 ayat (1) huruf a UU RI No.35 tahun 2009 Jo Pasal 55 ayat (1) ke-1 KUHP serta peraturan lain yang bersangkutan.

M E N G A D I L I

1. Menyatakan Terdakwa I. Dedy Sanjaja Bin Sukri dan terdakwa II. Kiki Pratama Bin Imron Als Nanang terbukti secara sah dan menyakinkan bersalah melakukan tindak pidana "PENYALAH GUNA NARKOTIKA GOLONGAN I BAGI DIRI SENDIRI"

(C) Author(s). This work is licensed under a Creative Commons Attribution 4.0 International License . Published by Postgraduate Program, Master of Laws, Faculty of Law, Universitas Sebelas Maret, Indonesia 
2. Menjatuhkan pidana terhadap Terdakwa I Dedy Sanjaya Bin Sukri terdakwa II. M.Kiki Pratama Imron Alias Nanang dengan pidana penjara masing masing selama 2 (dua) tahun;

3. Menetapkan masa penangkapan dan penahanan yang telah dijalani para Terdakwa dikurangkan seluruhnya dari pidana yang dijatuhkan;

4. Menetapkan supaya para terdakwa tetap berada dalam tahanan;

5. Menetapkan barang bukti berupa :

- 1 (satu) paket kecil Narkotika dengan berat netto 0,073 (nol koma tujuh tiga)gram. dirampas untuk dimusnakan

- 1(satu)unit sepeda motor Honda Beat BG-3513 AAR an NOVI YANTI dikembalikan pemiliknya an Novi Yanti.

6. Menetapkan para Terdakwa membayar biaya perkara masing masing sebesar Rp.2.500,(dua ribu lima ratus rupiah);

Penerapan hukuman dalam kasus ini dianggap tidak adil, pada Putusan Nomor: 161/Pid.Sus/2016/PN.Plg diatas. Pada kasus ini terdakwa didakwa sebagai pelaku atau pengedar narkotika, akan tetapi Majelis Hakim dalam putusannya menyatakan bahwa terdakwa adalah pemakai narkotika. Kasus tersebut dengan terdakwa bernama . Kedua terdakwa oleh Penuntut Umum didakwa dengan dakwaan pertama Pasal 114 Ayat (1) jo Pasal 132 Ayat (1) UU Narkotika dan/atau dakwaan kedua yaitu Pasal 112 Ayat (1) UU Narkotika, dan/atau dakwaan ketiga yaitu Pasal 127 Ayat (1) Huruf a UU Narkotika jo Pasal 55 Ayat (1) ke-1 KUHP.

Pada kasus ini terdakwa terbukti menguasai dan memiliki narkotika golongan 1 bukan tanaman sebanyak 1 paket sabu dengan berat 0,73 gram. Dari penemuan barang bukti tersebut seharusnya terdakwa dijerat Pasal 112 UU Narkotika. Pada kenyataannya Majelis Hakim menjatuhkan putusan dengan menyatakan bahwa terdakwa merupakan pemakai atau pecandu atau penyalahguna narkotik sehingga terdakwa dijatuhi sanksi pidana 2 tahun penjara. Sayangnya, penjatuhan hukuman yang menyatakan bahwa terdakwa merupakan pemakai atau pecandu atau penyalahguna narkotika tidak diikuti atau dilakukannya tes urin kepada kedua terdakwa untuk memperjelas apakah kedua terdakwa benar sebagai pecandu atau tidak. Terdakwa dalam kasus tersebut seharusnya dikenakan Pasal 112 UU Narkotika. ${ }^{12}$

\section{CONCLUSION}

Perjalanan panjang pengaturan narkotika di Indonesia diselimuti berbagai perdebatan pandangan, antara pendekatan kejahatan dengan pendekatan kesehatan, antara kedua perbedaan pandangan tersebut mengakibatkan tarik menarik kepentingan. Namun apabila dicermati lebih dalam, pembentuk UU Narkotika menyadari bahwa harus ada perubahan pendekatan penanganan terhadap pengguna narkotika, yaitu dari pendekatan pemidanaan kepada pendekatan kesehatan masyarakat dan perlunya perkembangan kebijakan global

${ }^{12}$ Benny Setiady Rasman, 2015. Penerapan Hukuman UU Narkotika Dianggap Tidak Adil. Diakses di https://www.mkri.id/index.php?page=web.Berita\&id=11877, pada tanggal 22 Juni 2021 pada pukul 20.30

(c) Author(s). This work is licensed under a Creative Commons Attribution-NonCommercial-ShareAlike 4.0 International License. Published by Postgraduate Program, Master of Laws, Faculty of Law, Universitas Sebelas Maret, Indonesia 
narkotika dengan memperhatikan kebutuhan pemenuhan atas Hak Asasi Manusia (HAM). Melihat kebutuhan atas pentingnya pendekatan HAM dalam kebijakan narkotika, maka secara nasional kebijakan narkotika pun akan lebih akuntabel jika memenuhi standar, karakteristik dan prinsip HAM. Perlindungan HAM menjadi bagian penting dalam reformasi kebijakan Narkotika.

Karena adanya perdebatan dari dua jenis pendekatan perbedaan tersebut, maka pada tahun 2009 muncul atau di ciptakannya UU tentang Narkotika yang hadir dengan beberapa ketidakjelasan pada pasal khususnya mengenai pengertian dan status antara penyalahguna, pecandu maupun korban penyalahguna narkotika. Oleh karena ketidakjelasan pengertian dan status tersebut, maka pengaturan lainnya menjadi simpang siur pada tataran implementasi. Hal ini secara tidak langsung akan membawa dampak besar terutama bagi pengguna narkotika.

Penyebab utama terjadinya ketidakjelasan dalam pasal yaitu dalam hal penerapan tindakan rehabilitasi medis dan sosial bagi pecandu maupun penyalahguna narkotika. Persoalan ini muncul ada pada ketentuan pemidanaan dalam Pasal 127 UU Narkotika. Di dalam pasal ini menggunakan istilah "penyalahguna" dan "korban penyalahgunaan narkotika". Dalam ayat (2) pasal menyatakan bahwa hakim dalam memutus wajib memperhatikan ketentuan Pasal 54, 55, dan 103 UU Narkotika, namun sangat disayangkan tidak adanya istilah penyalahguna, hanya ditemukan pengertian penyalahguna dilihat sebelah mata hanya sebagai korban, hal ini berdampak pada akses rehabilitas menjadi terbatas pada korban penyalahguna.

\section{REFERENCES}

\section{Buku}

Anggrayni, Alysa dan Yusliati. 2018. Efektivitas Rehabilitasi Pecandu Narkotika Serta Pengarubnya Terbadap Tingkat Kejahatan Di Indonesia ( Ponorogo: Uwais Inspirasi Indonesia)

Dahlan. 2017. Problematika Keadilan dalam Penerapan Pidana terhadap Penyalah Guna Narkotika ( Sleman: Deepublish )

Darwis. 2018. Menghukum Atau Memulibkan Suatu Tinjauan Sosiologis Tentang Tindakan Terhadap Penyalahguna Nafza (Makassar: CV Sah Media)

Edyyono, Supriyadi Widodo, Erasmus Napitupulu, Subhan Panjaitan, dkk. Memperkuat Revisi Undang-Undang Narkotika Indoneisa (Jakarta: Institute for Criminal Justice Reform)

Ishak, Desmiati, Rofiqul Umam ahmad, Theo Yusuf MS. 2020. Jagalah Dirimu dan Keluargamu dari "Api" Narkoba (Jakarta: Pimpinan Pusat Gerakan Nasional Anti Narkoba Majelis Ulama Indonesia)

Iskandar, Anang. 2019. Penegakan Hukum Narkotika (Rebabilitatif Terbadap Penyalah Guna Dan Pecandu, Represif Terbadap Pengedar) (Jakarta: PT Alex Media Komputindo)

Iskandar, Anang Iskandar. 2021. Politik Hukum Narkotika (Jakarta: PT Alex Media Komputindo)

(C) Author(s). This work is licensed under a Creative Commons Attribution 4.0 International License . Published by Postgraduate Program, Master of Laws, Faculty of Law, Universitas Sebelas Maret, Indonesia 


\section{Berita Online}

Abdulsalam, Husein. 2017. Dilema Hukuman Rebabilitasi Narkoba. diakes di https://tirto.id/dilemahukuman-rehabilitasi-narkoba-cvF8

Rasman, Benny Setiady. 2015. Penerapan Hukuman UU Narkotika Dianggap Tidak Adil. Diakses di https://www.mkri.id/index.php?page=web.Berita\&id $=11877$ 